\title{
Pathomorphological changes in the early postnatal period in a calf with abomasum rupture
}

\author{
Maria Sergeevna Mannova*, Lyudmila Vladimirovna Kletikova, and Nina Nikolaevna \\ Yakimenko \\ Ivanovo State Agricultural Academy named after D. K. Belyaev, Ivanovo, Russia, 153012, st. \\ Sovetskaya, 45, Ivanovo, Russia
}

\begin{abstract}
The main cause of the disease and death of calves in the early postembryonic period of development is a feeding disorder. The aim of the work was to analyze macro-and micromorphological changes in the digestive system of a calf with a rennet rupture. To achieve this goal, standard macro-and microscopic research methods were used. Macroscopic examination revealed thickening, erosion of the mucous membrane of the esophageal gutter rollers, accumulation of contents in the scar, mesh and book, hyperemia of the mucous membranes; thinning and rupture of the rennet wall; pronounced hyperemia of the mucous membrane of the small intestine, thickening of the mucous membrane of the thick section; an increase in mesenteric lymph nodes and a change in their consistency. Microscopically, the thickness of the epithelium, submucosal and muscle layer is most developed in the abomasum and was, respectively, 0.68-0.72 $\mathrm{mm}, 0.23-0.32 \mathrm{~mm}$ and $0.98-1.05 \mathrm{~mm}$. Villi were found in the folds of the scar, numerous well - developed longitudinally oriented protrusions were found in the book, lymphocellular clusters and bottom glands were found in the rennet; folds with well - developed crypts were found in the colon. Thus, as a result of feeding coarse feed, the deceased calf has catarrhal erosive lesions of the esophageal trough; serous-catarrhal abomasitis with signs of hemorrhagic with dilation and perforation in the cardiac part; hemorrhagic omasitis against the background of a book blockage; catarrhal reticulitis; catarrhal ruminitis and catarrhal enterocolitis.
\end{abstract}

\section{Introduction}

The neonatal period in calves is the interval from birth to the 8th day after birth, which is determined by morphofunctional changes due to the change of living conditions and adaptation of newborns to environmental factors $[3,6,11,12]$. During this period, significant changes occur in organs and systems. In the first days after the birth of a calf, its digestive system is insufficiently developed, where the abomasum is the only fully formed and functioning department. During the newborn period, the gastrointestinal tract of cattle undergoes changes due to the heterochronous development of membranes, tissues and their

\footnotetext{
${ }^{*}$ Corresponding author: mannova09@yandex.ru
} 
cells, the predominance of degenerative processes over regenerative ones. Adaptive rearrangements of epithelial, connective, muscular and nervous tissues, the intestinal wall, its mucous membrane, villi, crypts and duodenal glands are expressed in intensive tissue destruction, an increase in "migrant" cells, asynchronous development of the intestinal wall membranes, and cytochemical differentiation of cell protoplasm [5].

In the early dairy period, the digestive juices of the calf contain few enzymes, while the mother's milk contains all the enzymes that promote the digestion of milk nutrients. Despite the accumulated knowledge, the main cause of diseases of the gastrointestinal tract of young animals is still a feeding disorder. As a result of errors in the diet, the incidence of calves during the newborn period can reach $50-65 \%$, and mortality -90 percent or more $[4,6]$. With intensive animal husbandry and human intervention in the animal habitat, conditions for technological stress are created, leading to the death of young animals $[1,2]$.

The purpose of this study is to analyze macro - and microscopic changes in the rupture of the abomasum in a calf in the early postembryonic period of development.

\section{Materials and methods}

The study was performed at the Department of Obstetrics, Surgery and Non-Infectious Animal Diseases of the Ivanovo State Agricultural Academy in 2020. Sampling for microscopic examination was performed after a macroscopic analysis of the state of the digestive system of the fallen animal. The histological examination was carried out in accordance with the standard protocol.

\section{Results}

Examination of the digestive organs of the fallen animal found that the rollers of the esophageal gutter are thickened, pink in color with foci of redness; a bluish hue and more pronounced changes were noted in the bottom part and lips at the entrance to the book. On the right lip, the integrity of the mucous membrane with a size of $7.00 \times 13.00 \mathrm{~mm}$, oval in shape, is iolated (Fig.1).



Fig. 1. The mucous membrane of the reticulum and oesophageal groove with hemorrhages and erosive lesions (macro-preparation). 


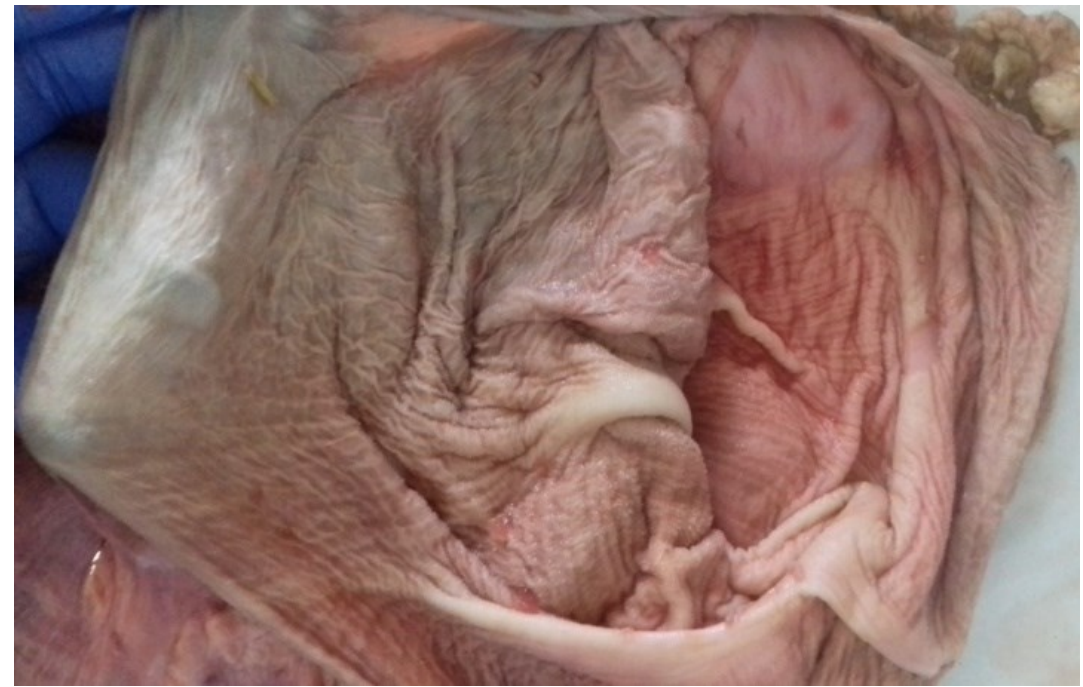

Fig. 2. The mucous membrane of the rumen with local redness (macropreparation).

In the scar, 3.00-4.00 kg of greenish-yellow contents of a dense consistency were found, the mucous membrane is yellow-gray in color with many papillae of different sizes and shapes (Fig. 2). The grid contains a small amount of dryish feed masses. The mucous membrane is pink in color with focal redness, collected in folds of various sizes, resembling network cells (Fig. 1).

The book is enlarged in volume, dense consistency, pink outside (Fig. 3). Along the serous surface of the book there is a cluster of hyperplastic, enlarged lymph nodes. In the area of the hole directed from the book to the abomasum, there are dry masses, the mucous membrane is dark cherry-red. The mucous membrane of the book is red-pink in color, collected in folds of different heights, between which there are dense dry feed masses (Fig. 4).

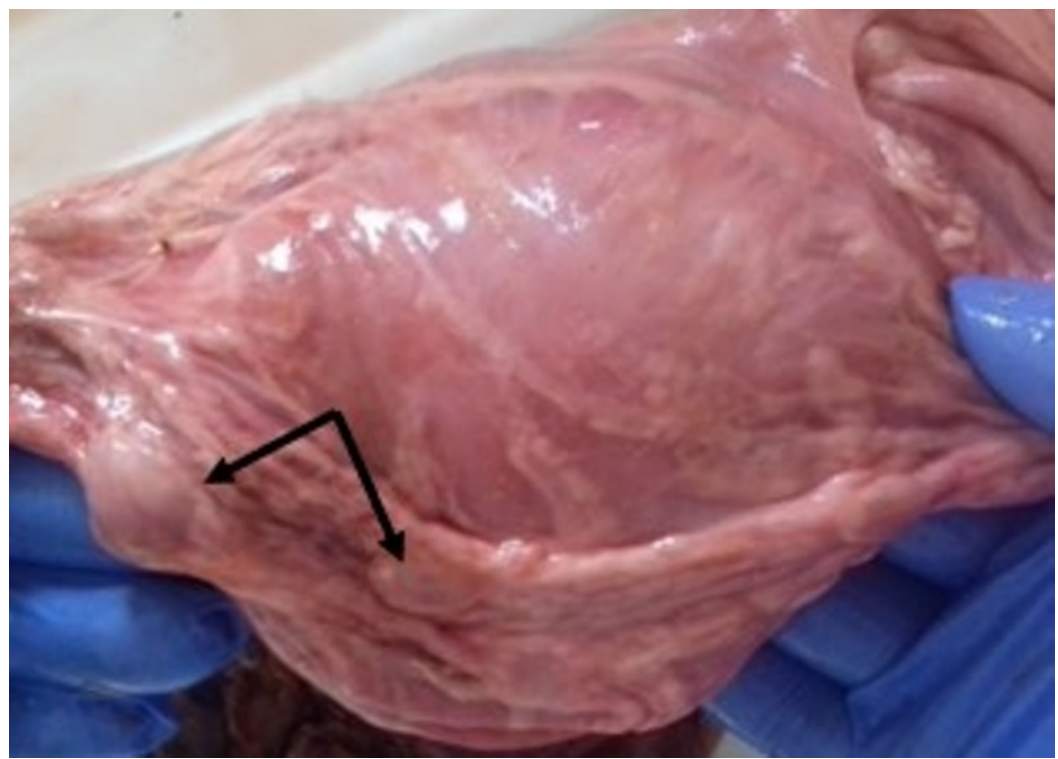

Fig. 3. Serous surface of the omasum (macropreparation) with hyperplastic lymph nodes. 


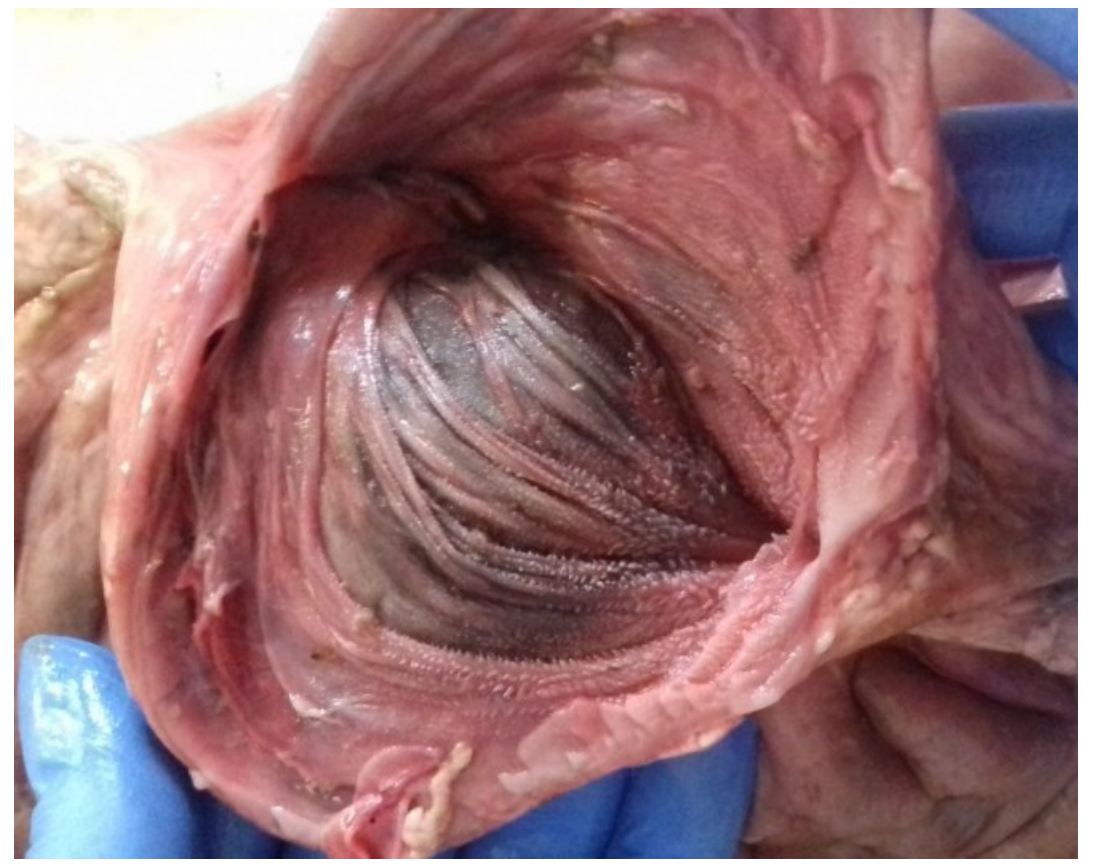

Fig. 4. The mucous membrane of the omasum (macropreparation).

On examination, the abomasum is enlarged in volume, it is colored dark cherry on the outside, due to the large curvature in the cardiac part, the shade becomes darker (Fig. 5). In the cardiac region of the rennet, stretching, thinning and violation of the integrity of the wall were revealed. The perforation hole is round-oval in shape with smooth edges, with a diameter of $38.00 \mathrm{~mm}$ (Fig. 6).

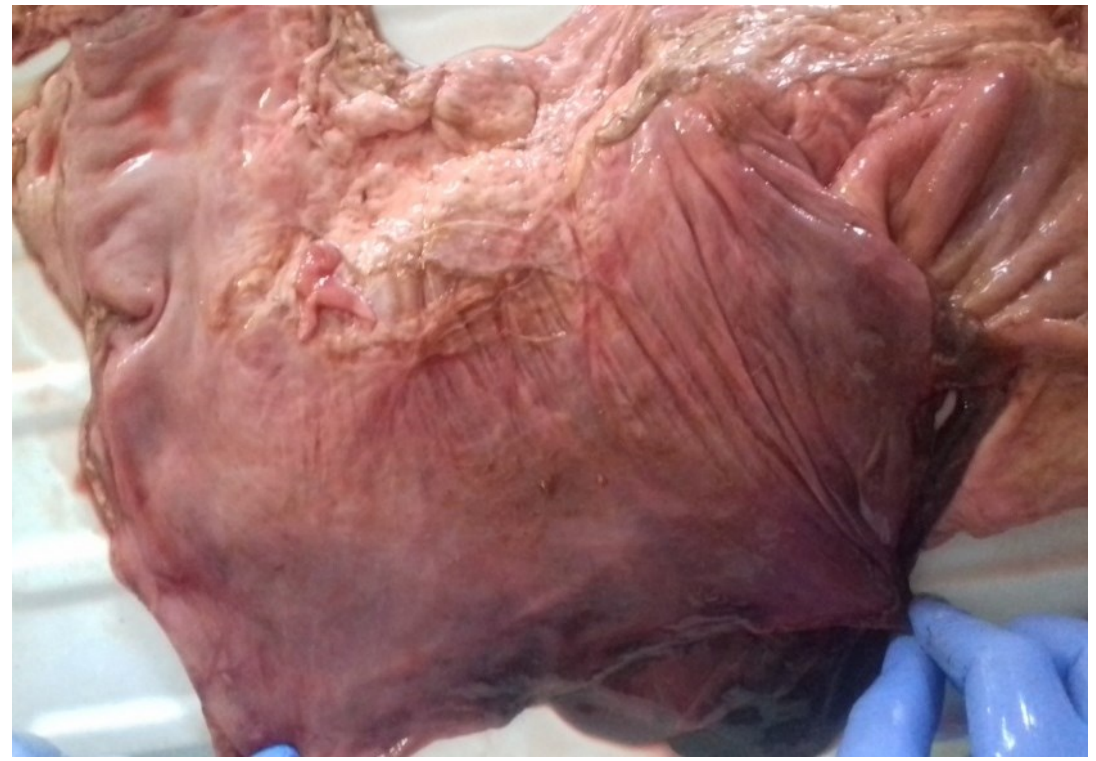

Fig.5. Serous surface of the abomasum (macropreparation). 


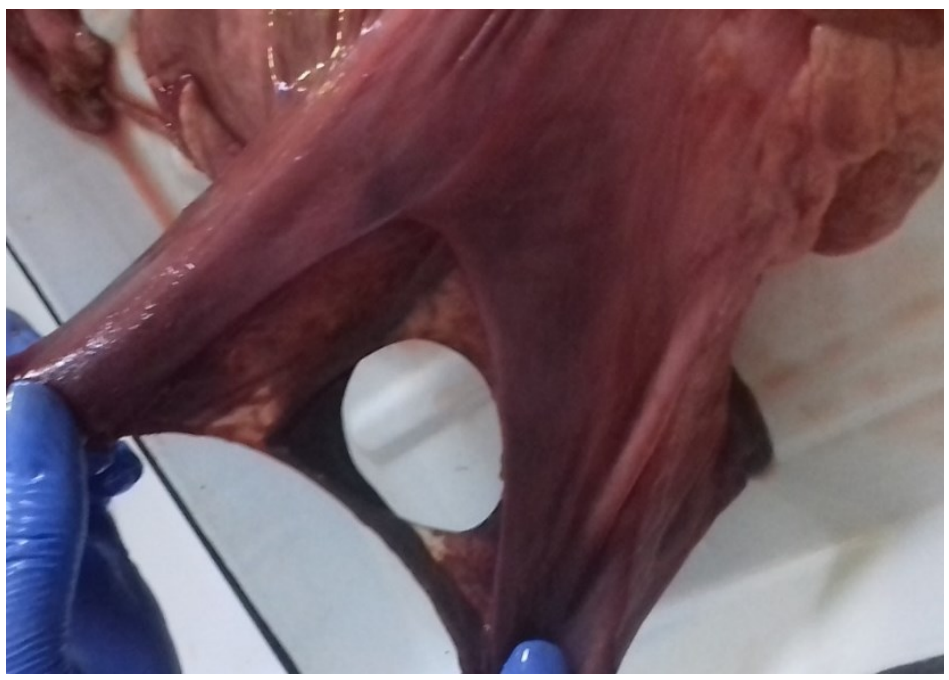

Fig. 6. Perforation of the abomasum wall (macropreparation).

The mucous membrane in the fundal and cardiac regions of the rennet is dark cherry-red, gelatinous consistency with bloody contents. The spiral folds are thickened, jelly-like, in the area of perforation of dark cherry color.

In the pyloric part of the abomasum, the mucous membrane is slightly reddened, edematous, thickened, with jelly-like foci, serous-mucous exudate is present in the places of contact of the feed masses with the mucous membrane (Fig. 7). The longitudinal folds in the pyloric part are slightly thickened, yellowish in color, reddened in places.

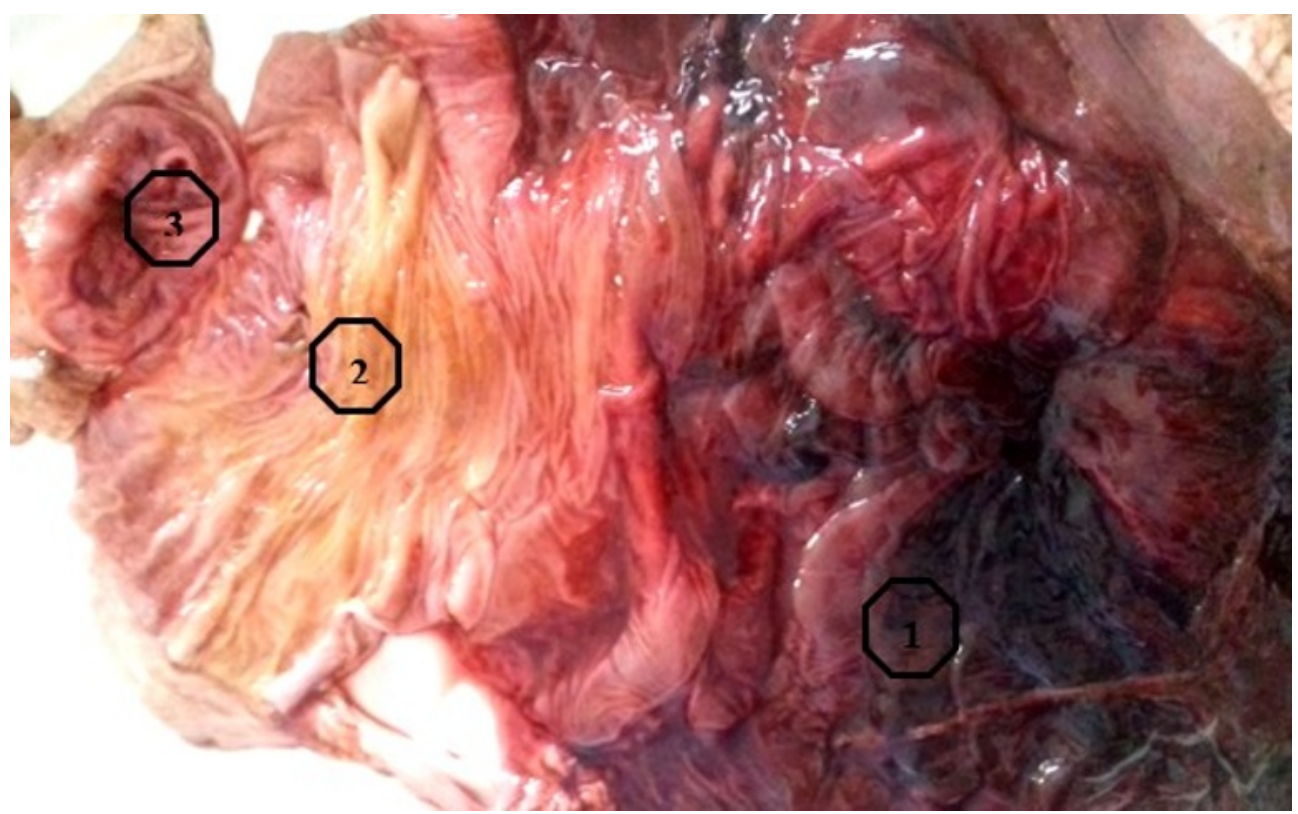

Fig. 7. The mucous membrane of the abomasum (macropreparation): 1 - gelatinous folds of the mucous membrane of the cardical part of the abomasum - hemorrhagic type of inflammation; 2 - fundus area of the abomasum pyloric part with signs of serous-catarrhal inflammation; 3 - sphincter area.. 
There is a small amount of yellow-brown content in the small intestine (12-duodenum, jejunum and ileum). Outside, the 12-digit and jejunum are pink-red in color. The mucous membrane is from red to dark cherry color, covered with a thick, viscous mucus with brown veins. Mesenteric lymph nodes are enlarged, dense consistency, elastic, gray in the section (Fig. 8).

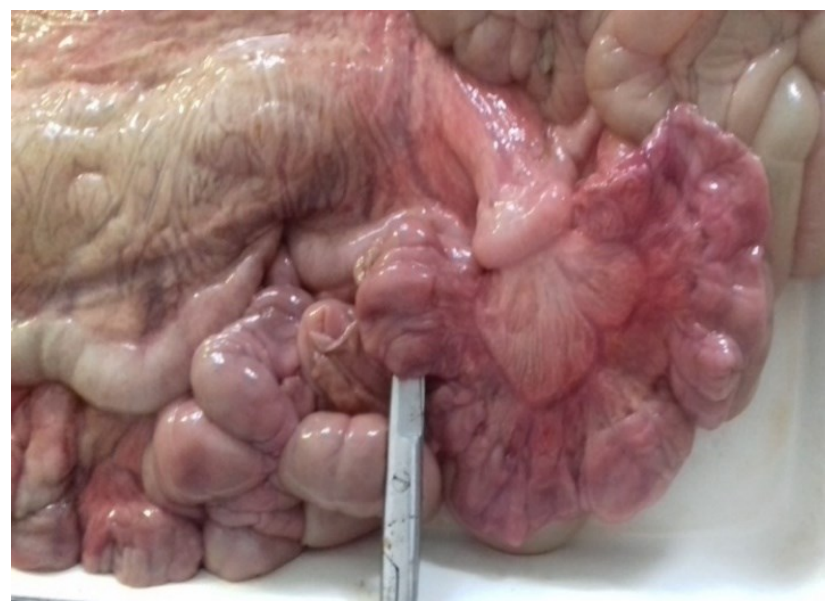

Fig. 8. Macropreparation of the calf's small intestine part with signs of catarrhal inflammation.

The large intestine: the blind, colon and rectum are moderately filled with a semi-liquid gray-brown mass with a specific smell. The mucous membrane is pale gray, shiny, in the area of the spiral labyrinth of the colon, the mucosa has a longitudinal folding, thickened, covered with a viscous gray mucus (Fig. 9).

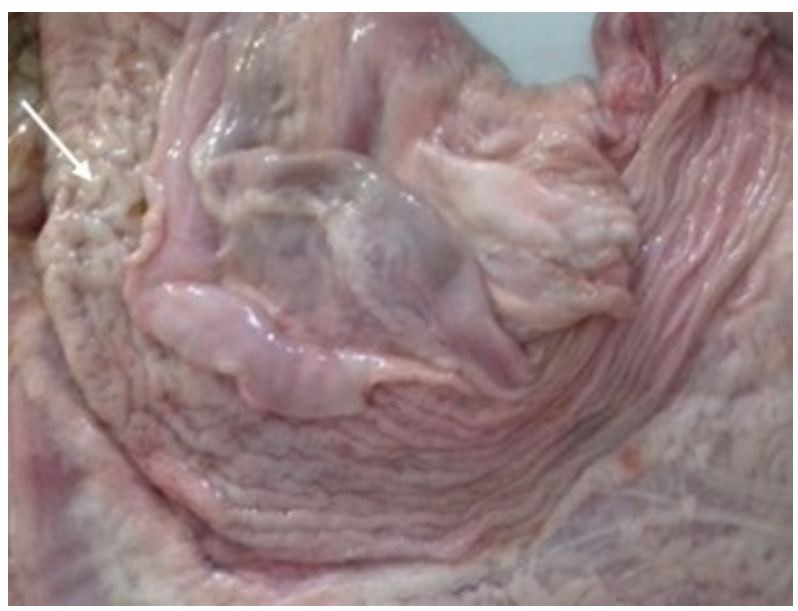

Fig. 9. The mucous membrane of the spiral colon of the middle intestine with signs of catarrhal inflammation (macropreparation).

Microscopically, it was found that the mucous membrane of the esophageal gutter was sent out by a multilayer flat non-corneating epithelium (MPNE), which together with the submucosal layer forms folds, the thickness of the epithelium was $0.18 \mathrm{~mm}$, the submucosal layer was $0.27-0.55 \mathrm{~mm}$. Below them is a well-developed muscle layer consisting of two ring-shaped and one longitudinal layer of smooth muscle tissue (Fig. 10). 


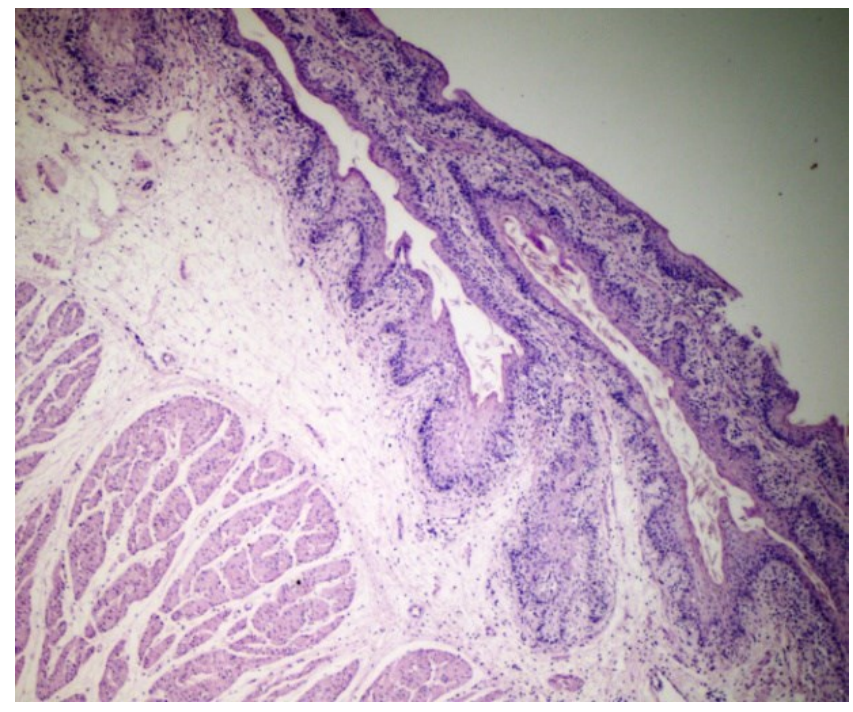

Fig. 10. Histological structure of the oesophageal groove wall Coloring: hematoxylin and eosin. Eyepiece $\times 10$, objective $\times 40$.

The mucosa of the scar is sent out by MANE, which, together with the submucosal base of loose fibrous connective tissue (RVST), containing a large number of elastic fibers, forms protrusions (folds), inside which there is a cluster of lymphoid cells. The thickness of the mucosa varies from 0.09 to $0.13 \mathrm{~mm}$, the submucosal base-from 0.17 to $0.60 \mathrm{~mm}$, the height of the villi in the folds $-0.51-0.85 \mathrm{~mm}$. The muscle membrane is represented by two layers: a well-developed internal circular and an external longitudinal one. The serous membrane is represented by RVST and mesothelium (Fig. 11).

The mucosa of the mesh is represented by the MPNE, which, together with its own plate of the mucosa with a thickness of 0.03-0.18 mm, forms a rimmed surface (Fig. 12).

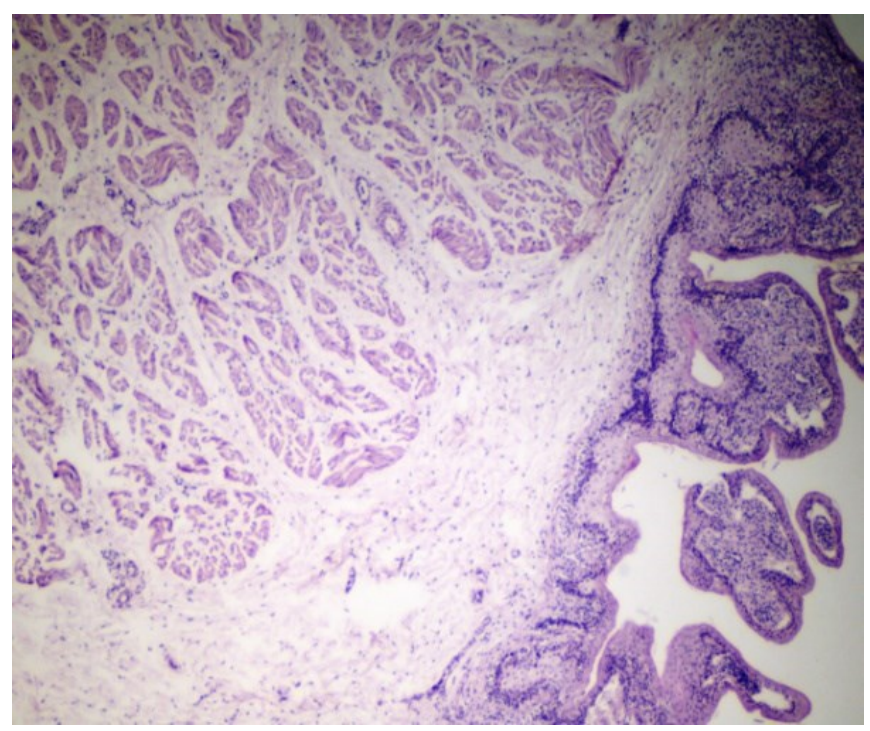

Fig. 11. Histological structure of the oesophageal groove wall Coloring: hematoxylin and eosin. Eyepiece $\times 10$, objective $\times 40$. 


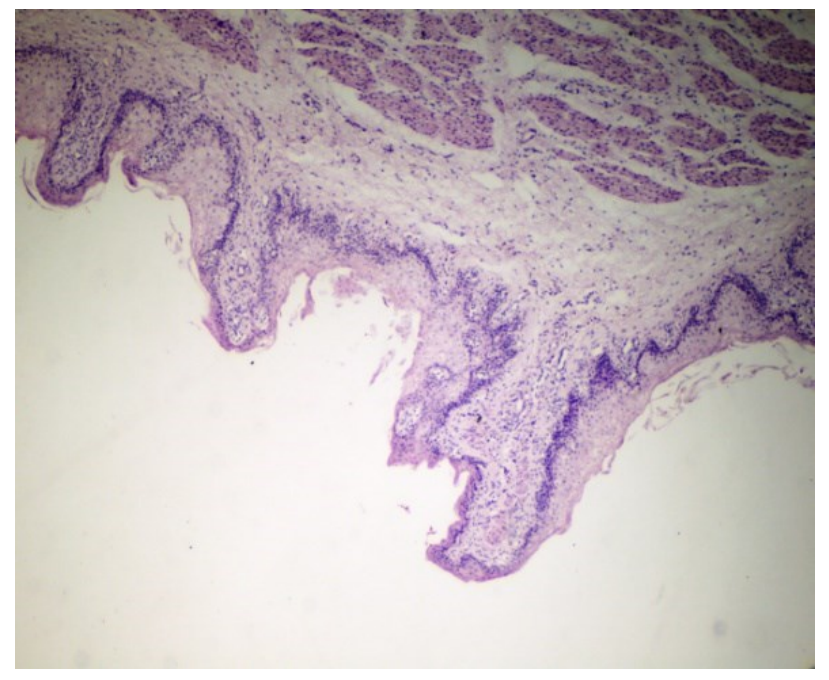

Fig. 12. Histological structure of the reticulum wall. Coloring: hematoxylin and eosin. Eyepiece $\times 10$, objective $\times 40$.

The submucosal base is RVST with a thickness of $0.24-0.37 \mathrm{~mm}$. Under them there is a well-developed muscle layer consisting of two annular and one longitudinal layer of smooth muscle tissue, outside there is a serous membrane consisting of RVST and mesothelium. At the same time, the epithelium in the area of the tip of the protrusion is exfoliated more intensively than at the base of the folds. The mucous membrane of the book, like other chambers of the pre-ventricles, was sent to ME, its thickness is from 0.08 to $0.11 \mathrm{~mm}$ (Fig. $13)$.

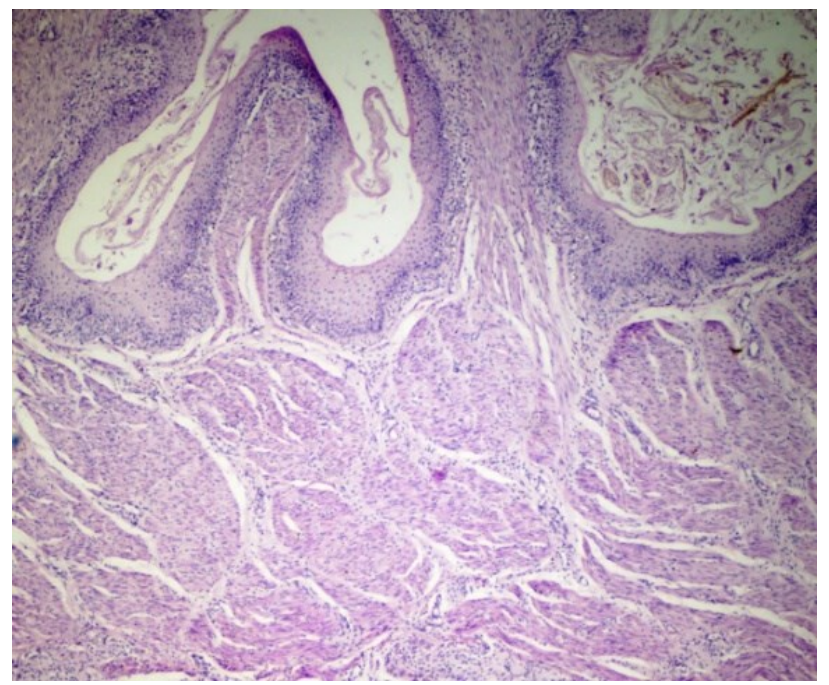

Fig. 13. Histological structure of the omasum wall. Coloring: hematoxylin and eosin. Eyepiece $\times 10$, objective $\times 40$.

The epithelium and its own plate of the mucous membrane (SPZO) with a thickness of $0.07-0.13 \mathrm{~mm}$ form numerous, well-developed longitudinally oriented protrusions with a height of 0.43 to $0.75 \mathrm{~mm}$. As in the grid, the epithelium on the tops of the folds is sloughed off more intensively. The height of the epithelium at the top is $0.04 \mathrm{~mm}$, at the base- $0.18 \mathrm{~mm}$. 
The muscle layer is represented by two ring-shaped and one longitudinal layer of smooth muscle tissue with a thickness of $0.89-1.08 \mathrm{~mm}$, the outer, serous membrane, with a thickness of $0.05 \mathrm{~mm}$, consists of RVST and mesothelium.

The mucous membrane of the abomasum is lined with a single-layer prismatic epithelium, in the SPSO there are lymphocellular clusters and bottom glands (fundal, pyloric and cardiac). The thickness of the mucous membrane (epithelium and MTR) was $0.68-0.72 \mathrm{~mm}$, the submucosal base is represented by a loose connective tissue (PCT) with a thickness of $0.23-0.32 \mathrm{~mm}$. The muscle membrane is $0.98-1.05 \mathrm{~mm}$ thick, consists of three layers of smooth muscle tissue: oblique, circular and longitudinal. The serous membrane is $0.05 \mathrm{~mm}$. In the pyloric part of the abomasum in the area of the sphincter, the wall forms a powerful finger-like protrusion consisting of a mucous membrane 0.78-1.17 mm thick and a submucosal base $1.19 \mathrm{~mm}$ thick (Fig. 14-15).

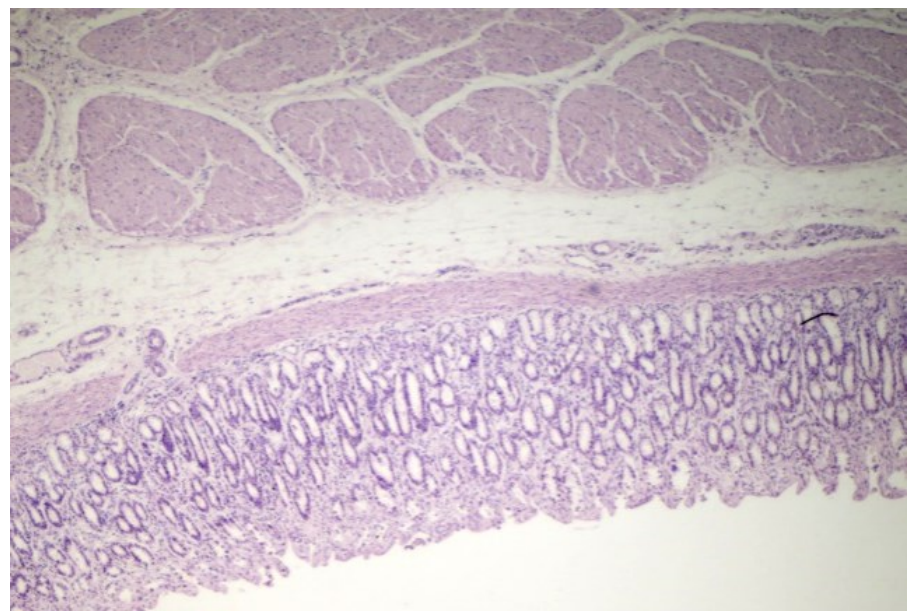

Fig. 14. Histological structure of the abomasum wall. Coloring: hematoxylin and eosin. Eyepiece $\times 10$, objective $\times 40$.

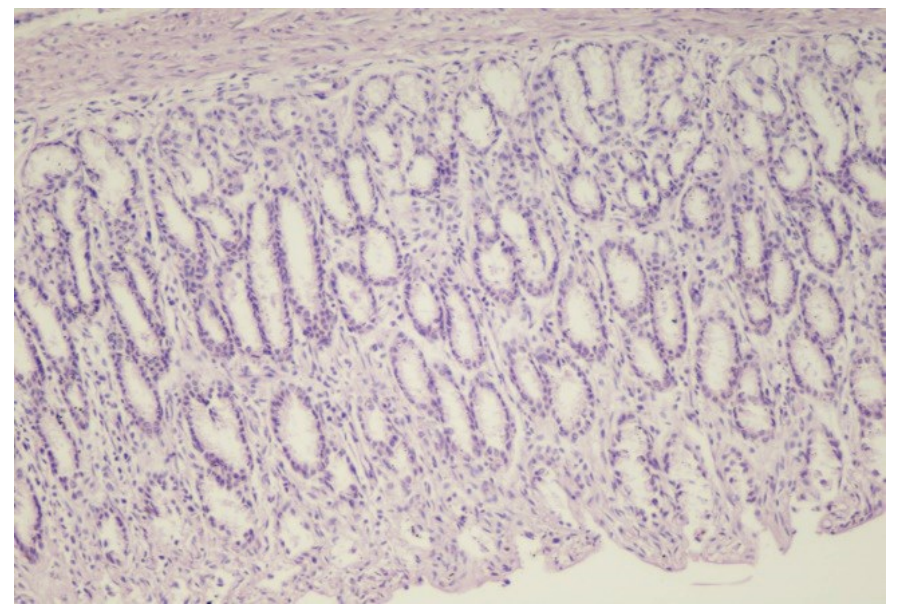

Fig. 15. Histological structure of the abomasum wall. Coloring: hematoxylin and eosin. Eyepiece $\times 10$, objective $\times 100$.

The mucosa of the duodenum 12 forms villi lined with a high prismatic epithelium (Fig. 16). 


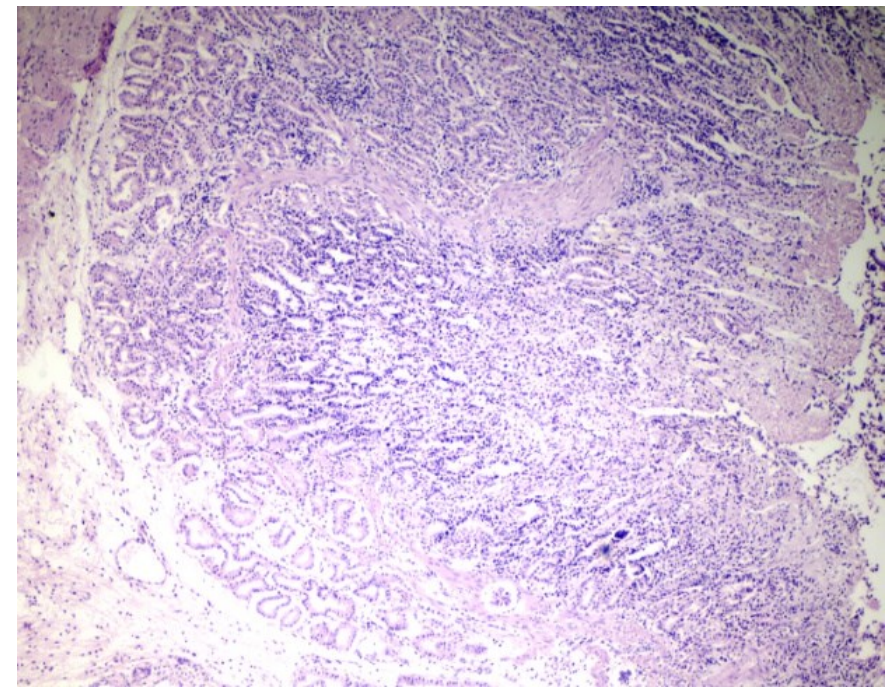

Fig. 16. Histological structure of the duodenal wall. Coloring: hematoxylin and eosin. Eyepiece $\times 10$, objective $\times 40$.

The epithelium contains a large number of edged, goblet-shaped and endocrine cells. Going deeper into the SPSO, the epithelium forms crypts. The muscular plate of the mucous membrane (MPSO) is represented by several layers of smooth muscle cells. The thickness of the mucous membrane is $0.53-0.91 \mathrm{~mm}$, the submucosal base is $0.72-0.78 \mathrm{~mm}$. The latter is represented by PCT with well-developed duodenal glands of a complex tubular structure, which is typical only for the duodenum 12. The muscle membrane consists of circular and longitudinal layers with a thickness of $0.99-1.17 \mathrm{~mm}$. The thickness of the serous membrane was $0.27-0.38 \mathrm{~mm}$.

The mucous membrane of the jejunum is represented by a single-layer cylindrical epithelium, $0.03 \mathrm{~mm}$ thick (Fig. 17).

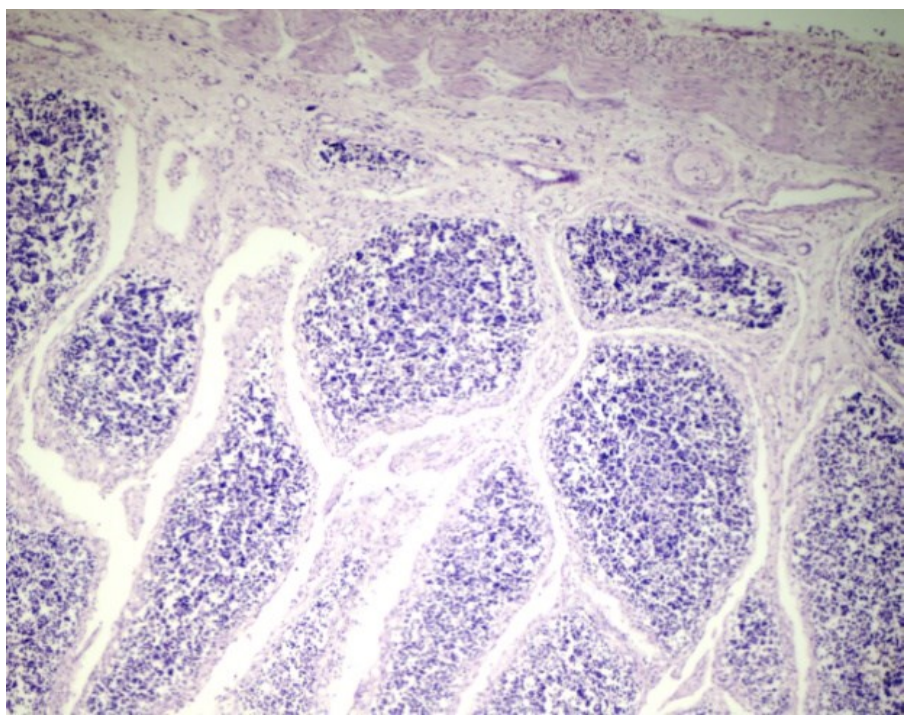

Fig. 17. Histological structure of the jejunum wall. Coloring: hematoxylin and eosin. Eyepiece $\times 10$, objective $\times 40$. 
The muscle membrane has a smaller thickness compared to the previous section and was $0.20 \mathrm{~mm}$. The submucosal base is represented by PCT with numerous blood, lymphatic vessels and nerve plexuses with a thickness of $0.26-0.50 \mathrm{~mm}$. The regional lymph node is covered with a capsule with a thickness of 0.045-0.055 microns from the surface, under the capsule is a cortical substance; the follicles are not morphologically formed, they are defined as denser clusters of lymphocytes without signs of a reactive center, reticular tissue is visualized. The border of the cortical and medulla is indistinct, the latter is blood-filled, the "loose" location of lymphocytes is noted.

The mucous membrane of the colon forms folds with well-developed simple unbranched tubular glands-crypts. The single-layer cylindrical epithelium of crypts is dominated by goblet-shaped cells. The height of the mucous membrane is $0.175-0.215 \mathrm{~mm}$, the submucosa is $0.129-0.155 \mathrm{~mm}$. In the submucosal base, there are lymphoid follicles with a size of $0.053 \times 0.213 \mathrm{~mm}$. The thickness of the muscle and serous membranes is $0.59-0.91 \mathrm{~mm}$ and $0.05 \mathrm{~mm}$, respectively.

The mucous membrane of the rectum forms weakly pronounced folds, sent by a prismatic single-layer epithelium, in the crypts - goblet-shaped cells (Fig. 19).

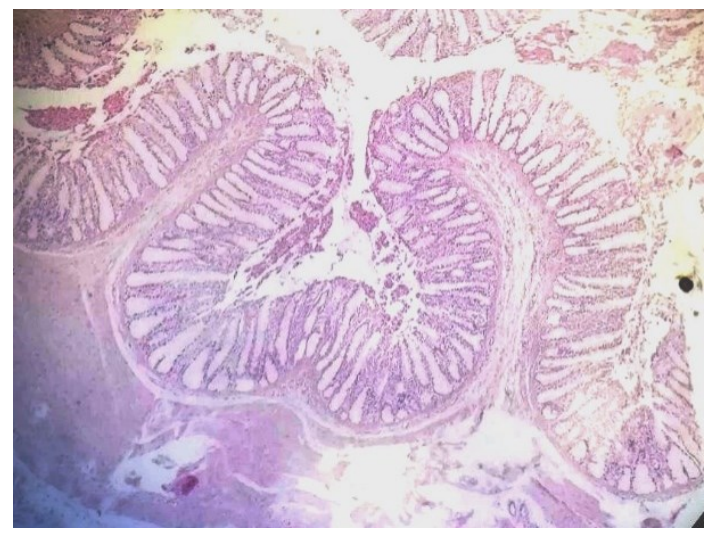

Fig. 18. Histological structure of the middle intestine wall. Coloring: hematoxylin and eosin. Eyepiece $\times 10$, objective $\times 40$.

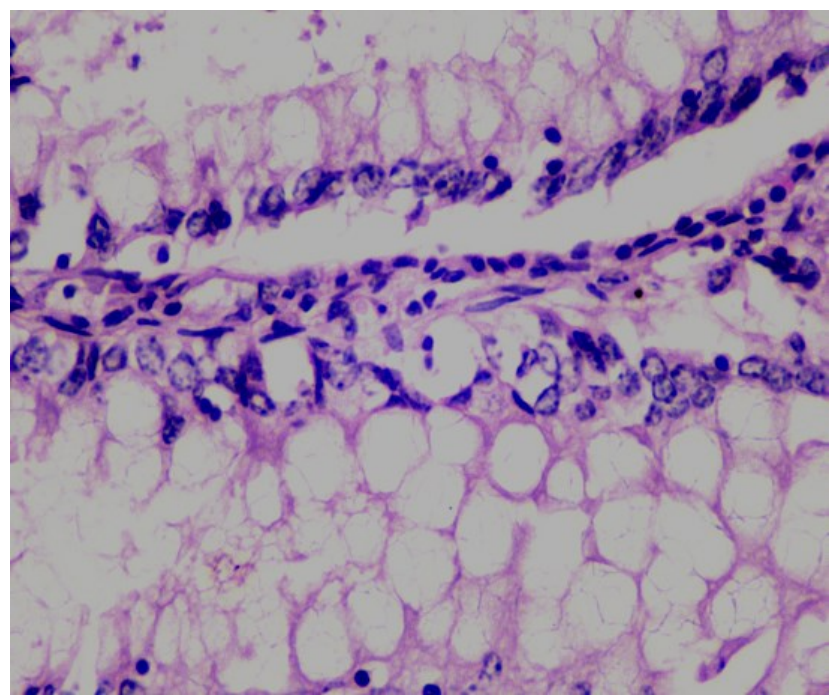

Fig. 19. Epithelium of the rectum. Coloring: hematoxylin and eosin. Eyepiece $\times 10$, objective $\times 400$. 
The height of the mucous, submucosal and muscular membranes is $0.33-0.54 \mathrm{~mm}, 0.06-$ $0.13 \mathrm{~mm}$ and $0.50-0.85 \mathrm{~mm}$, respectively. There are no lymphoid elements - sollitic follicles - in the submucosal layer. From the outer surface - Adventitia from the PCT.

\section{Discussion}

Individual development of an organism implies a complex of genetically programmed morphological, biochemical and physiological changes $[8,9,10,11,12]$. In seven-day-old calves, the gastrointestinal tract is not functionally and morphologically formed, there are no enzymes involved in the digestion of coarse and concentrated feeds, the "esophageal gutter reflex"is expressed. Only with age, as a result of unique transformations of the digestive system, as the scar develops, its colonization by microorganisms, the calf physiologically passes from a pseudomonogastric animal to a functioning ruminant animal [7].

Feeding the calf with concentrated feed caused thickening and erosion of the esophageal gutter rollers, accumulation of dense consistency contents in the rumen, mesh and book, hyperemia of the mucous membranes. In addition to redness, thinning and rupture of the abomasum wall, the calf has a red-cherry-colored mucous membrane of the small intestine, covered with a thick, viscous mucus with brown veins, the mucosa of the thick section is thickened, covered with a viscous mucus of gray color. Mesenteric lymph nodes are enlarged, of a dense consistency.

During microscopic examination, the mucous membranes of the digestive tract were sent out by a multilayer flat non-corneating epithelium. The thickness of the epithelium and submucosal layer, respectively, in the esophageal gut, scar, mesh, book, rennet, duodenum, colon, rectum was $0.18 \mathrm{~mm}$ and $0.27-0.55 \mathrm{~mm} ; 0.09-0.13 \mathrm{~mm}$ and $0.17-0.60 \mathrm{~mm} ; 0.03-0.18$ $\mathrm{mm}$ and $0.24-0.37 \mathrm{~mm} ; 0.68-0.72 \mathrm{~mm}$ and $0.23-0.32 \mathrm{~mm} ; 0.08-0.11 \mathrm{~mm}$ and $0.07-0.13 \mathrm{~mm}$; $0.53-0.91 \mathrm{~mm}$ and $0.72-0.78 \mathrm{~mm} ; 0.33-0.54 \mathrm{~mm}$ and $0.06-0.13 \mathrm{~mm}$. In the grid and the book, a more intense peeling of the epithelium at the tops of the folds was found.

Villi were found in the folds of the scar, numerous well - developed longitudinally oriented protrusions were found in the book, lymphocellular clusters and bottom glands were found in the rennet; folds with well - developed crypts were found in the colon. The muscle layer is well developed in all parts of the gastrointestinal tract.

\section{Conclusion}

As a result of the passage of coarse feed, the deceased calf has catarrhal erosive lesions in the esophageal trough; serous-catarrhal abomasitis with signs of hemorrhagic with dilation and perforation in the cardiac part; hemorrhagic omasitis against the background of a book blockage; catarrhal reticulitis; catarrhal ruminitis and catarrhal enterocolitis.

\section{Acknowledgements}

The study was carried out at the expense of the federal budget by order of the Ministry of Agriculture of Russia in 2020.

\section{References}

1. H. B. Baymishev, B. V. Krishtoforova, V. V. Lemeshchenko, Biological foundations of veterinary neonatology: monograph, 452 (2013)

2. V. P. Degtyarev, S. V. Fedorov, G. M. Udalov, Neonatology and diseases of newborn calves: monograph, 157 (2016) 
3. A. A. Kataranov, Clinical and immunological characteristics of newborn calves and non-drug methods of correction of their immunodeficiency, 24 (2005)

4. Zh. N. Miholap, Normalization of morphohistochemical abnormalities in the digestive organs of calves with dyspepsia with the proobiotic drug "Intenstevit", 127 (2007)

5. L. P. Teltsov, T. A. Romanova, I. V. Dobrynina, E. O. Mikhailovskaya, A. G. Krasovskaya, I. G. Muzyka, A. I. Shadrina, Proceedings of the Orenburg State Agrarian University, 20-1(4), 73 (2008)

6. D. N. Kharitonik, G. A. Tumilovich, Morphofunctional changes in the body of young cattle and poultry against the background of the use of mineral-vitamin and probiotic drugs: monograph, 219 (2019)

7. Q. Diao, R. Zhang, T. Fu, Animals (Basel), 9(8), 490 (2019)

8. P. Gorka, Z.M. Kowalski, P. Pietrzak, A. Kotunia, W. Jagusiak, R. Zabielski, Journal of Dairy Science, 94(6), 3002 (2011)

9. J. M. Vivo, A. Robina, S. Regodón et al, Histology and Histopathology, 5(4), 461 (1990)

10. K. K. Knott, P. S. Barboza, R. Terrybowyer, Journal of Mammalogy, 86(1), 121 (2005)

11. K. Dieho, A. Bannink, I.A.L. Geurts et al., Journal of Dairy Science, 99(3(1)), 2339 (2016)

12. V. M. Shpygova, O.V. Dilekova, A.N. Kvochko, V.A. Meshcheryakov, V.V. Mikhaylenko, Dusunen Adam, 10(1), 2063 (2019) 